\title{
LA TRADICIÓN DE LOS DISTICHA CATONIS: ENTRE LA AUCTORITAS MEDIEVAL Y LA RENOVATIO HUMANISTICA
}

\author{
Juan Carlos Sesé Sanz \\ Licenciado en Filología Clásica. Zaragoza
}

La finalidad del presente estudio es apreciar en qué medida una tradición literaria que permanece desde la latinidad tardía hasta el Renacimiento es tributaria de cada época.

\section{LOS DISTICHA CATONIS EN LA TRADICIÓN MEDIEVAL}

Quién fue Catón, autor del poemario que comentamos, y dónde vivió ha sido objeto de muchas conjeturas y no pocas confusiones. El único escritor que manifiesta su influencia dentro de la Antigüedad es Comodiano, poeta cristiano cuya actividad literaria no se ha podido datar con certeza, pues fluctúa entre los siglos III y.V. No obstante, la primera explicitación del nombre de Catón aparece en una carta de Vinciniano, procónsul de Africa en época del Emperador Valentiniano, fallecido en 375 . A partir de estos datos, algunos investigadores han sugerido que la difusión de los Disticha Catonis en Africa justifica las concomitancias estilísticas y versificatorias con otras obras norteafricanas. Por ello, concluyen, el autor de los dísticos tuvo que ser un retórico de este lugar. ${ }^{1}$ Por su parte, otros han preferido creer el testimonio de un manuscrito de París del siglo X que declara que su autor era oriundo de Córdoba. ${ }^{2}$

Tampoco es injustificado considerar que el autor era Catón, el Censor (234-149 a.C.), según el sentido de autoría que tenía la Antigüedad, en la que prima más la adscripción a una

1 Monceaux, Paul, Les Africains, Paris, 1894, p. 359. Cit. por Johnson Chase, Wayland: The distic of Cato. University of Wisconsin, Madison, 1922, p. 1 y ss.y Pauly-Wissowa: Realencyclopädie der classichen altertumswissenchaft, Verlag, Stuttgart, 1958.

2 Plessis, Frederic, La Poesie Latine, Paris, 1909, p. 664 y Goldberg, Max O.: Die Catonischen Distichen während des Mittelalters in der Englischen und Französischen Literatur, Leipzig, 1883, p. 8. 
tradición compositiva y temática. El nombre de Catón iba asociado a la literatura sapiencial en forma de consejos prácticos de carácter vital y con fines pedagógicos. ${ }^{3} \mathrm{En}$ fin, no faltan los escépticos que, encabezados por John of Salisbury, autor en el siglo XII de Polycraticus, consideran que es una obra anónima, sin más.

Sea como fuere, la opinión más extendida y también más cauta supone que la obra fue compuesta entre el año 117 y el 324 por un desconocido escritor que vivía en la parte occidental del Imperio Romano. En torno al siglo V se atribuyó a Catón y no es hasta el siglo XVI cuando Scaligero le dio el prcenomen Dionysius, en conformidad con el testimonio del historiador Simeon Bosius, de objetividad actualmente desacreditada.

En conjunto, se trata de una colección de preceptos morales, versificados en 320 dísticos hexamétricos que se distribuyen en cuatro libros de métrica monótona. Van dirigidos al hijo del autor en un tono didáctico que impregna toda la obra. Así, son frecuentes vocativos, construcciones antitéticas, un vocabulario poco dificultoso abundante en nuda verba, imperativos, expresiones reiterativas y breuitas expositiva. Cada libro va prologado por unos versos proprépticos; esto es, que invitan a la lectura y aconsejan memorizar la obra con fines prácticos. Lo más probable es que sea un añadido medieval a una obra previa.

La colección de dísticos ha contado, a lo largo del tiempo, con una gran variedad de títulos: Dicta Catonis, Dicta M. Catonis ad filium suum, Libri Catonis Philosophi, D. Catonis Disticha de Moribus ad Filium, Disticha Moralia D. Catonis..., siguiendo las diferentes atribuciones de la obra. Si sumamos los problemas de autoría, fechación, y titulación, comprenderemos la labilidad del texto.

El poemario se enmarca dentro de la poco original poesía pagana del llamado renacimiento constantino-teodosiano, aunque la colección de máximas morales se remonta al mundo griego, cuestión que por su extensión no abordamos. La marginalidad con que es tratado por la crítica literaria responde a su inferioridad respecto de las composiciones de la época augústea, pero comparte con la producción contemporánea el àcademicismo y la tendencia arcaizante, al menos en su temática.

En el Medievo se convirtió en el libro de texto por antonomasia de los escolares. En efecto, este ludus litterarius, que contenía enseñanza gramatical, dada la sencillez de su factura y la sentenciosidad de su contenido, era considerado como la mayor herencia institucional de la Escuela Gramática Romana, en una época en que la cultura, asediada por el ambiente de confusión que producían las invasiones germánicas, se refugia en iglesias y monasterios. Los niños eran preparados para cantar en el coro catedralicio y para su instrucción, junto a los salmos, memorizaban los Disticha Catonis, con los que se ejercitaban en gramática y en lectura. El pensum era necesario en una época en que la escasez de material escriptorio limitaba la posesión de los textos.

La mordacidad y agudeza de la sabiduría práctica que contenían los aforismos de Catón contribuyó a su popularidad y uso generalizado. Así, el reputado teólogo del siglo XII Walter

3 Schanz, Martin, Geschichte der Römischen Literatur p. 34 en Handbuch der Klassichen Altertumswissenshaft, ed. Müller, München, 1905. 
Map llamó a Catón «el más sabio después de Salomón» ${ }^{4}$ y su coetáneo John of Salisbury dijo que con los dísticos los niños son instruídos regularmente en los preceptos de la virtud. Del mismo modo se expresa Aberlardo y otros representantes del Renacimiento Carolingio. Catón se convirtió en una autoridad junto a Virgilio y los Santos Padres. Su popularidad fue tanta que, ya en el otoño de la Edad Media, Chaucer, describiendo la ignorancia de un carpintero dirá: «He knew no Catoun, for his wit was rude» (The Miller's Tale v. 119).

\section{LA REVALORIZACIÓN HUMANíSTICA}

No deja de sorprender que un manual tan difundido en la Edad Media continuara siendo apreciado en el Renacimiento. Para entender este fenómeno hay que situar la cosmovisión de cada época. Los humanistas del Renacimiento tenían confianza en una renouatio que transmutase la cultura y la vida y que instaurara una libertad de iniciativa, heredera de la tradición romano-cristiana. Se vuelve a los orígenes de la Antigüedad clásica y se abominan las tinieblas del Medievo. Su más encendido propulsor, Cola di Rienzo, exhortará al pueblo romano con las siguientés palabras: «Quítese la lúgubre vestimenta de la viudedad, revístase con la púrpura nupcial [...] vuelva a tomar el cetro de la justicia».5

En la península italiana la renouatio tenía tintes políticos: lo que se pide es que Roma se convierta en la cabeza del mundo de una uniuersa sacra Italia. Los humanistas reaccionan frente al bizantinismo de la escolástica medieval, que consideran un paréntesis en la latinidad. Ahora la eloquentia aúna vida y pensamiento en oposición a la charlatanería logicista, vacía y generalizadora.

\section{II.1. Del Medievo al Renacimiento}

Contrariamente a como se suele explicar, el paso de la Edad Media al Renacimiento hay que explicarlo, más que desde parámetros culturales, desde un cambio de religiosidad. En la época medieval todos los aspectos de la vida humana y todas las disciplinas se confundían con la religión; como queda patente en la teocracia en el campo político y en la cristianización de autores paganos en el campo literario. Así, se lee en Virgilio un anuncio de la venida del Mesías, en Aristóteles se demuestra un Dios personal o en Platón se prefigura un Moisés ético. El impulso racionalizador bajomedieval difunde una deuotio moderna, opuesta a la escolástica especulativa y a las manifestaciones supersticiosas.

A partir de ahora, el instrumento para llegar al conocimiento religioso no será la lógica, sino la retórica. Valla vio en el abuso logicista de la teología el origen de todas las herejías. Así pues, el agustinismo sucede al aristotelismo y el predominio de la razón lógica es sustituido por el de la razón filológica, con base en Cicerón y Séneca. Se van a preferir maestros de vida

4 Map, Walter, De Nugis Curialium, distinctio V, cap. V en Anecdota Oxoniensia, Medieval and Modern series, Part. XIV, Oxford, 1914.

5 Cit. por Garin, Eugenio, El Renacimiento italiano, Ariel, Barcelona, 1986. 
(historiadores, literatos, poetas...) en lugar de filósofos, de modo que, por ejemplo, de San Agustín se aprecian no las elucubraciones teológicas del De Trinitate, sino las meditaciones humanas de las Confessiones. Al lado de la demanda de una reforma religiosa está presente una reforma de las costumbres.

La propia palabra que designa a esta nueva actitud o filosofía de la vida resume el ideal pedagógico. Como bien explica Francisco Rico ${ }^{6}$ humanista es el profesor de los studia humanitatis, al igual que legista es el versado en leges. Por eso, la humanitas no debe entenderse como mera $\phi 1 \lambda \alpha v \theta \rho \omega \pi \imath \alpha$, sino como $\pi \alpha \downarrow \delta \varepsilon \imath \alpha$. Lo distintivo del hombre hay que entenderlo como oratio y no como ratio preestablecida, como pretendía la tradición socráticoplatónica: «frente a las certezas intemporales de la linguística medieval, los humanistas preconizaban el criterio del uso real» (Rico, op. cit., p. 510).

$\mathrm{La}$ reforma educativa, pues, discurre paralela. Frente al exasperado formalismo de la escuela medieval, ahora se potencian las capacidades del hombre; Rabelais describe la reeducación de Gargatúa, empachado con los pedantescos manuales de los profesores de La Sorbona, que llama «sorbonagros», gracias a su nuevo maestro. Esta escuela (la «Orden de la Libre Voluntad»), que se preocupaba por la espontaneidad, por la alegría saludable, los ejercicios físicos, los clásicos, el contacto directo con la realidad circundante, tenía por lema: «Fay ce que vouldras».

Tres procesos son simultáneos a este movimiento humanístico:

1.- el descubrimiento ejemplar de los clásicos.

2.- el estudio del latín.

3.- la defensa de la poesía.

Aunque en Valla la afirmación de la lengua latina tenía un carácter nacionalista, lo cierto es que a través de ella los humanistas toman conciencia del origen común de su cultura. La crisis de la unidad lingüística, piensan, supuso la ruptura de la unidad espiritual de los hombres. Urgía por tanto restaurarla. En nuestro país, los rigores gramaticales hicieron del latín un «rito de pubertad», a base de repetir las Introductiones latina de Nebrija, como acusa Maldonado. ${ }^{7}$ Por contra, en las escuelas italianas los alumnos se ejercitaban en discursos para adquirir un estilo armonioso.

En cuanto a la defensa de la poesía pagana, exaltada al lado de la religiosa suponía la defensa de una humanidad no dividida en religiones o imperios. Independientemente de los estamentos sociales, en ella se encontraba un vínculo nuevo. Como se ve, estos tres elementos no son incompatibles con la vigencia de los Disticha Catonis.

\section{II.2, La vigencia de los Disticha Catonis}

Durante el Renacimiento se difunden por toda Europa los Disticha Catonis, en varias ediciones traducidos a las lenguas vernáculas. Fueron usados en las Escuelas de los Jerónimos,

6 Rico, Francisco, Humanismo y ética en Historia de la ética, ed. Victoria Camps, Crítica, Barcelona, 1988 pp. 507-540, donde el concepto de humanitas se apoya en Aulo Gelio XIII, 17 y en Jaeger, Paideia.

7 Maldonado, Juan, Parcenesis ad litteras, ed. E. Asensio y J. Alcina, Madrid, 1980, § 46. 
bajo la supervisión de Melancthon, el preceptor de Alemania, como se ha dicho, y por Johann Sturm en la Escuela de Estrasburgo. También nuestro Vives cita a Catón en alguna momento.

Las ediciones se sucedieron en el quinientos. Destacan la más elaborada de Erasmo, con traducción griega de Planudes (1539), la de Maturinus Corderius, el famoso preceptor de Calvino (1561) y la de Scaligero en Leyde al fin de la centuria (1508). La primera, la más accesible, tras un saludo al gimnasiarca de Lovaina, fustiga en el prólogo a los escolásticos:

[...] quibus duo quidam opusculum hoc contaminauerant, quorum alter insulsis<s>ime rhetoricatur homo ipsa, infantior infantia, alter ineptissime philosophatur; uterque

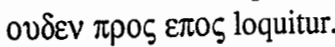

Luego, confesada la incertidumbre de la autoría (Erasmo dice que se atribuye a Catón por ser propio de este autor las sentencias) y la delimitación del texto, arremete contra los estoicos, que llama «combatientes de vicios» («uitilitigatores»): «Sed interim clamabit uitilitigator aliquis hui Theologum in tam friuolis uersarinugis?». La posición de Erasmo en la polémica entre el severo estoicismo y el atractivo epicureísmo queda manifiesta en su diálogo Epicureus (1533). Si Valla trató de conciliar las dos posturas en su teoría de la uoluptas ccelestis, expuesta en De uero falsoque bono, el Rotterodamo toma partido por el Jardín de Epicuro. El diálogo entre Hedonius y Spudæus concluye que el hecho de que el epicureísmo niegue los placeres que comportan algún dolor supone una paz de conciencia que debe ser admirada por el cristiano. Sin embargo, Erasmo prescinde de la física epicúrea, para no entrar en el espinoso terreno de un conflicto con la teología, materia que le distanciaba tanto de Lutero como de la ortodoxia católica. Por eso, el prólogo termina diciendo que las sentencias se pueden encaminar hacia las buenas costumbres («ad bonos mores conducibiles»).

Pasa a continuación a defenderse de las posibles acusaciones de inmoralidad con un argumento ex auctoritate: si desestiman la obra de Catón, también están despreciando la de Teognis, Focílides y Pitágoras, del mismo modo que Terencio se defendía del recurso de la contaminatio aludiendo a su uso por parte de Plauto y Nevio. Termina el prólogo con unas recomendaciones pedagógicas. Ediciones posteriores cuentan además con una traducción al griego, realizada por Planudes en Viena en 1523. Al lado de cada dístico inserta comentarios, unos de carácter religioso-moral (por ejemplo § II, 19: Pugnant inter se luxus et avaritia) y otros filológico. Ya desde el principio asoman ideas típicamente erasmianas («Animus est Deus» que recuerda el «homo homini aut deus aut demon») o tópicos como el tema de los vitia pro virtutibus.

Pero sigamos con la influencia de los dísticos de Catón. Al mismo tiempo de su difusión, los Disticha Catonis eran entusiásticamente parodiados en Alemania y Francia por los goliardos durante los siglos XV y XVI. También aparecía en 1605 una parodia inglesa, siempre en lengua vernácula, titulada School of Slovenrie or Cato turn'd wrong side outwarde. En fin, en el mundo anglosajón fueron prescritos en algunos colegios, durante el quinientos y el seiscientos. El propio Cardenal Wolsey los enseñó y no es impensable que fueran recitados en las aulas en que se formaron John Milton y Oliver Cromwell. 
Las ediciones del siglo XVIII evidencian el optimismo y énfasis en la educación propie de la época, hasta el punto de que un hagiógrafo suizo incluyó a Catón en el santoral. Entre las ediciones modernas, la más aceptable es la de Emilius Bæhrens, en el tomo III de los Poetce Latini Minores, Leipzig, 1881.

Traducciones castellanas son la edición de Diego de Linares (1501), Simeón de Pedraza (1517) o más tardía de Ricardo de Mondéjar (1629). Una curiosa versión fue la de Pedro de Castro, ${ }^{8}$ titulada Castigos y doctrinas que dio el sabio Catón a su hijo, impresa en Medina del Campo en 1544, según refiere. Son: 143 estrofas de cuatro versos de arte mayor polimétricos que traducen, con la correspondiente amplificatio, los dísticos de Catón, si bien de forma irregular. Así, por ejemplo, el primer dístico del primer libro de Catón aparece traducido en la estrofa 96. Impreso en letra gótica, termina el libro con un colofón cristiano, de la que por supuesto carece el latino: «Hijo, a dios te encomiendo y a la Virgen María. / A Dios gracias»,

Una estrofa en especial ( $\$ 100)$ va a tener influencia posterior en la literatura española:

De los hombres reboltosos te deues arredrar, a las buenas costumbres deues allegar, de persona del mundo no quieras de tratar, que no biue en el mundo ninguno sin pecar.

Junto a rasgos estilísticos como la cesura interna, así como la rima fácil de los infinitivos, hay que señalar que traduce el dístico catoniano $\S$ I, 5, en edición de Erasmo:

Si uitam inscipias, hominum si denique mores

Cum culpent alios, nemo sine crimine uiuit.

Cervantes utilizará ese segundo hemistiquio del segundo verso en una de sus Novelas Ejemplares El licenciado Vidriera, en el momento en que Tomás Rodaja elogia a Nemo como prototipo virtuoso, siguiendo tal vez la crítica al estoicismo fariseico de los que ensalzan la virtud que no practican: «nemo nouit patrem, nemo sine crimine uiuit, nemo sua sorte contentus, nemo ascendit in cælum».

\section{EL SIGNIFICADO DEL LIBER DISTICHORUM DE VERINO}

En la Biblioteca Universitaria de Zaragoza hay un volumen impreso en letra gótica que contiene varios libros de tradición medieval. Parece que son obras impresas autónomamente para luego ser recogidas y encuadernadas en un único volumen, caracterizado por incluir obras pedagógicas, bajo el epígrafe del autor de la primera obra: Catón. Las ediciones conjuntas de

8 Castro, Pedro de, op. cit. 1544, en Los pliegos poéticos de la colección del Marqués de Morbecq (s.XVI), ed. A. Rodríguez Moñino, Madrid, 1962. 
libros eran entonces habituales. La edición de Erasmo mencionada contiene obras de otros escritores. En efecto, el primer libro menciona la fecha de 1508, mientras que el silencio del segundo es roto por un escoliasta anónimo que en la portada escribió a pluma: «Cæsaraugustæ typis excussum / anno Domini MDX».

De Comptentu mundi, ${ }^{9}$ incluida en la encuadernación conjunta, era una obra también muy difundida de enseñanza religioso-moral. Recordemos que tanto esta obra como la de Catón pertenecían a los auctores octo, ${ }^{10}$ considerados auctoritates en época medieval y vituperados por los humanistas (son los manuales que atontan al Gargantúa de Rabelais).

En el Liber Distichorum se contiene un poemario de Michele Verino, en el que a la manera catoniana compone dísticos hexamétricos de idéntica temática y factura. La edición corre a cargo de Juan Sobrarias, según explica en el prólogo, a propuesta de Jorge Cocci, el famoso impresor zaragozano del quinientos, debido a la «parua latinarum litterarum eruditione» que tienen los impresores. Enumera las características de estos versos de Verino que le sirvieron para su propio provecho ( «ad meam utilitatem optime custodita adseruabam») y eran «las más dignas de aprenderse» («scitu dignissima») por las siguientes razones: «eleganti condita artificio, latinissimis uerbis constructa, et summam uirtutem redolentia».

Tras el prólogo Sobrarias introduce un Carmen elegiacum de materia libri en dísticos, en el que, una vez mencionada la ejemplaridad de la tradición de los Disticha Catonis, enumera las composiciones que le dedicaron a Verino poetas como Poliziano, Seratico, Michelotio, Seralcino y Dieronymo, todas ellas incluidas en la edición mencionada junto a los dísticos de Sobrarias.

Quién fue Michele Verino nos lo explica el propio Sobrarias en verso, si bien es información que se debe contrastar con otros perfiles biográficos. ${ }^{11}$ Aunque vivió su última etapa en Florencia, había nacido en Menorca y había sido educado en Roma por Paolo Saxia, al que dedica sus dísticos, y por el gramático Ronciglione. Según dice Michaud, «son caractère était mélancolique, sa pronontiation difficile et il était naturellement silencieux». Se cartea con Dino, Ridolfi, los hermanos Conisioni, entre otros y se entrega, desde la adolescencia, a una «virginité perpetuelle» (sic). Cayó enfermo y desoyó el consejo de casarse para recuperar la salud que le dieron los médicos. A la edad de 18 años falleció en sus años florecientes. Esta muerte se producía en 1487 y supuso para su padre un grave golpe del que no se volvería a recuperar. El mito del joven precoz de temprano fallecimiento dio lugar a muchas composiciones encomiásticas, varias de las cuales introdujo Sobrarias en su edición. El poeta alcañizano tuvo oportunidad de contactar con estos autores durante su estancia italiana.

9 También llamado Chartula, porque comenzaba con el verso «Chartula nostra tibi portat Reynalde salutem» y estaba incluido en las compilaciones de textos escolásticos preparatorios, junto a Ianua de Donato («Ianua sum rudibus primam cupientibus artem») y a Eua Columba de Prudencio.

10 Estos auctores octo eran, además de los autores de los Disticha Catonis y De comptentu mundi, Teodulus, Facetus, Floretus, Esopo versificado, el Tobias de Mateo de Vandome y las Parábolas de Alain de Lille.

11 Michaud, Biographie universelle, Paris, 1968, s.v. 
El padre del joven, Ugolino Verino, era más conocido en calidad de maestro de elocuencia. A él dirigió Savonarola el opúsculo Apologeticus de ratione poetica artis, en el que explicita su desprecio a la poesía:

\begin{abstract}
En los versos de los poetas paganos nacieron grandes engaños diabólicos, porque, así como el diablo enseñó aquellos versos para la adoración de sí mismo y para alimentar la superstición humana, también dejó en ellos su soberbia vanidad. [...] Y de estos engaños, de estas burlas pueriles van alimentando las tiernas almas de los jóvenes y su intelecto puro y virgen lo llenan, primero de falsedad, y luego de infamia y abominable superstición de los idólatras.
\end{abstract}

op. cit. Venecia, 1543, pp, 35 y ss.

Estas recomendaciones educativas no estaban muy alejadas de las que proponía Giovanni Dominici, cardenal de la Santa Iglesia Romana, con su elogio del silencio («la humildad no habla») y la recomendación de dar bastonazos a los jóvenes, tanto si lo merecen como si no, pues «en el primer caso pagan justamente; en el segundo tienen el mérito de tener paciencia. Pero siempre los golpes y bastonazos son útiles para ellos $» .^{12}$ Como se puede observar, Michele Verino fue más bien una víctima de los rigores de la educación que todavía aleteaba por Europa.

La edición que Sobrarias lleva a cabo de los dísticos de Verino es una edición escolar, como lo evidencian los epígrafes con que intitula cada dístico y el propio título de la obra menciona (Ad scholasticum utilitatem). Verino es consciente de la tradición catoniana en el dístico 7: «Tu, Cato, uel censor nostris scribere libellis; / hæc farrago mei carminis ista seges». Pero, junto a un elogio de Marcial (dist. 9) los versos de Verino son sintomáticos de su propia educación con epígrafes tan curiosos como De falsis gaudis, Peccatum est obex inter animum et deum, Femina peccati gluten, o todavía más evidente para un lector de El nombre de la rosa: Inmodicus risus non est sapientis, o el propio De risu, que coincide con el libro perdido de -Aristóteles, núcleo argumental en la obra de Umberto Eco.

La difusión de los dísticos de Verino fue especialmente activa en la Corona de Aragón, donde éste y otros libri minores eran los textos escolares de Barcelona, Valencia y Perpiñán, como mencionan Asensio y Alcina en el prólogo de la obra de Juan Maldonado mencionada, además de Zaragoza, como queda demostrado. Lo cierto es que Maldonado, desde su cargo de inspector de sacerdotes, reprocha a los aspirantes al sacerdocio su desconocimiento de la gramática latina, porque sí conocen los Disticha Verini o De Comptentu Mundi, pero ignoran a S. Jerónimo, San Ambrosio o S. Agustín (§ 37-38). El celo que pone Maldonado se refleja en su frase sentenciosa Clericus sine litteris asinus bipes est strudendus fuste. Tuvo, por tanto, la obra de Verino una buena propagación, pero su secillez compositiva alimentaba la pereza y los sacerdotes no leían a otros sutiles teólogos.

12 Dominici, Giovanni, Regola del governo di cura familiare, Florencia, 1860. Cit. por Garin, E.: op. cit. p. 77 . 


\section{LOS SOBRARII DISTICHA}

Los Joannis Sobrarii disticha están contenidos dentro del Liber Distichorum con que es homenajeado póstumamente Michele Verino. Además de las composiciones de los poetas arriba mencionados, cierra la obra una de la mano de Sobrarias.

Los datos sobre la vida de Sobrarias nos los proporcionan diversas fuentes. ${ }^{13}$ Nace en Alcañiz, su «fecunda ingeniorum mater», hacia 1460. Continuó sus estudios en el Colegio Mayor San Clemente de Bolonia, donde publicó Ad Diuum Clementem Hymnus. En 1504 regresa a su Alcañiz natal, donde ejercerá la medicina, hasta que cuatro años después es llamado a Zaragoza «ut humanitatis studi publice profiteretur», apunta Asso del Río. Después de 1513 realizó un segundo viaje a Italia, donde pronunció un discurso ante Carlos V y los embajadores que allí se encontraban. En 1516 escribe a Cocci una carta en la que le comunica que va a continuar su magisterio en su villa natal. Fallece el 22 de Abril de 1528, según constaba en la partida de defunción de la actualmente desaparecida iglesia de Santa María en Alcañiz. A los funerales asistió, camino de las Cortes de Monzón, el propio rey Carlos V.

Escribió, entre otros, el poema Panegyricum carmen (1511) en loor de Fernando V, compañero suyo, libros de poesías como De laudibus Alcagnicii (1506), además de su producción pedagógica, como una edición de Virgilio para uso de sus discípulos (1513). Mantuvo correspondencia con Marineo y Nebrija.

Como ya he ido señalando, Asso del Río realizó una edición en Amsterdam en 1783 de la composición que sirve de colofón a los Disticha Catonis editados por el poeta alcañizano. La lectura de los Sobrarii Disticha nos remonta más a Catón que a los rigores de Verino. Retoma el tono didáctico y no censorio que caracterizaba al escritor latino y, como él, ensalza las virtudes y no condena abiertamente los vicios, si no de forma tímida. También hace alarde, como en su anterior Panegyricum carmen, de sus conocimientos mitológicos con un tratamiento libre, toda vez que no se aleja de la moral cristiana. Leída la obra, los dísticos parecen consejos que el maestro alcañizano daba a sus alumnos. Verino ofrece un panteón en el que cada dios encarna determinado vicio u objeto característico: Ceres la gula, Baco la ociosidad, Venus el lecho nupcial, Hércules es un proxeneta...

La originalidad de Sobrarias en esta composición es muy escasa en cuanto a la temática, tan plagada de tópicos que calcan el modelo catoniano. El acierto de Sobrarias hay que buscarlo en su facilidad versificatoria. Los Disticha Catonis acusan cierta rigidez en la expresión y sobriedad en la utilización de recursos estilísticos, ausentes ambas en los dísticos de Sobrarias. Las aportaciones del poeta alcañizano conviene contextualizarlas en el seno de una tradición literaria, según he tratado de explicar, con las innovaciones oportunas a la nueva cosmovisión y en el seno del ambiente educativo, mediante la anotación y prologación de la obra, así como

13 Blasco de Lanuza, Historia eclesiástica, Zaragoza; Latassa: Biblioteca antigua y nueva de escritores aragoneses, ed. M. Gómez Uriel, Zaragoza, 18; Sancho, Nicolás: Descripción [...] de la ciudad de Alcañiz y sus afueras, Alcañiz, 1860; Gómez de la Cortina, Joaquín.: Catalogus librorum doctoris J. Gómez de la Cortina, t. VIII, Matriti, 1862. 
la recopilación de poemarios laudatorios que se añaden al Liber distichorum de Verino. Esta obra acusa ya los primeros brotes de denuncia de la autoctoritas medieval: «Non te dicentis moueat reuerentia, sed quid / dixerit attendas, qua ratione prolet».

En definitiva, lo que diferencia la recepción medieval de los Disticha Catonis de la humanística estriba en que la primera enfatiza el hecho de ser escrita por una auctoritas y por ende es una obra modélica no sólo en su aspecto moralizante y universal, sino también educativo, en tanto que en el Renacimiento se prima su carácter creativo, como obra abierta a emulaciones, y particularizador al mismo tiempo, es decir, aplicable a un lugar y momento concreto. Se comienza a abominar la bibliocracia, al decir de Max Weber, en favor de una sabiduría encarnada en un contexto. Podemos afirmar que en la Edad Media se memorizaban los Disticha Catonis, en el tránsito al Renacimiento se imitan, en la pluma de Verino, y en época humanística se recrean, de la mano de los poetas italianos y del compilador alcañizano Sobrarias.

\section{TABLA CRONOLÓGICA}

\section{Arzobispo Alonso}

1460 Nace en Alcañiz Juan Sobrarias

1474 El Papa Sixto IV escribe una bula para organizar los estudios zaragozanos

1487 Fallece en Florencia a los 18 años Michele Verino

1493 Gonzalo García de Santa María publica Catón en latín y en romance

1500 C. Sedulio publica Paschale cum annotationibus Johannis Sobrarice

1504 Sobrarias regresa a Alcañiz, tras su formación en Bolonia. Es armado caballero por Fernando el Católico

1506 Coci imprime Las CCC de Juan de Mena

1506 Sobrarias compone De laudibus Alcagnicii

1507 Coci imprime Tragicomedia de Calisto y Melibea

1508 Coci imprime Los quatro libros del Amadís de Gaula. Sobrarias edita los Disticha Catonis

1510 Sobrarias edita el Verini Liber Distichorum, donde incluye sus Disticha

1511 Compone Sobrarias un Panegyricum carmen en honor de Carlos V

1512 Nace en Zaragoza el historiador Jerónimo Zurita

1513 Sobrarias realiza una edición escolar de Virgilio y realiza su segundo viaje a Italia

1517 Nace en Zaragoza el numismático y paleógrafo Antonio Agustín. Se presenta en Zaragoza la Corte del Emperador Carlos V

1519 ?Edición de Erasmo de los Disticha Catonis en Estrasburgo

1520 Coci imprime Las Décadas de Tito Livio, la más bella impresión del quinientos español

1523 Planudes traduce al griego los Disticha Catonis en Viena

1524 Probable traslado a Zaragoza de Miguel Servet

1528 Coci imprime Enchirindon de Erasmo de Rotterdam. Fallece el 22 de Abril Juan Sobrarias en su Alcañiz natal

1533 El erasmista Mateo Pascual es procesado en Roma 
1540 Pedro Bermuz y Bartolomé de Nájera ocupan la oficina tipográfica de Coci

1542 Se funda la Universidad de Zaragoza

1546 Fallece Coci

1598 Scaligero edita en Leyde los Dionysii Catonis Disticha

1783 Asso del Río realiza una edición de sus poemas Panegyricum carmen y Sobrarii Disticha en Amsterdam

\section{BIBLIOGRAFÍA}

MAESTRE, J.M.: El humanismo alcañizano del siglo XVI, Univ. de Cádiz, Cádiz, 1990. 